Articles

2015

\title{
Profiles of the Sources of Science Self-Efficacy
}

Jason A. Chen

College of William \& Mary, jachen@email.wm.edu

Ellen L. Usher

University of Kentucky

Follow this and additional works at: https://scholarworks.wm.edu/articles

Part of the Education Commons

\section{Recommended Citation}

Chen, Jason A. and Usher, Ellen L., "Profiles of the Sources of Science Self-Efficacy" (2015). Articles. 13. https://scholarworks.wm.edu/articles/13

This Article is brought to you for free and open access by W\&M ScholarWorks. It has been accepted for inclusion in Articles by an authorized administrator of W\&M ScholarWorks. For more information, please contact scholarworks@wm.edu. 
Running head: PROFILES SOURCES OF SELF-EFFICACY

Profiles of the Sources of Science Self-Efficacy

Jason A. Chen

The College of William and Mary

Ellen L. Usher

University of Kentucky

Contact Information:

Jason A. Chen

The College of William and Mary

School of Education

PO Box 8795

Williamsburg, VA 23187-8795

Phone: (757) 221-6201

Fax: (757) 221-2988

jchen04@gmail.com 


\begin{abstract}
The purpose of this study was to investigate (a) the latent profiles that arise from middle and high school students' $(N=1225)$ reported exposure to information from the four hypothesized sources of self-efficacy; (b) the relationships between these latent profiles and science selfefficacy and science achievement; and (c) the differences in latent profiles as a function of implicit theory of science ability, gender, and grade level. Results revealed that a four-class solution fit the data the best. Results support past findings indicating that mastery experiences are a powerful source of self-efficacy. Furthermore, there seemed to be an additive benefit of drawing from multiple sources simultaneously. Gender did not predict membership in these four profiles, but implicit theory of ability and grade level did. The results show that students in the most adaptive profiles drew from multiple sources of efficacy-relevant information and espoused a strong belief in the plasticity of their science abilities, whereas those who were in the least adaptive profiles exhibited a high degree of negative affect and held a fixed view of science ability.
\end{abstract}

Keywords: Self-efficacy; Implicit Theories of Ability; Science Education; Latent Profile Analysis; Adolescents 


\section{Profiles of the Sources of Science Self-Efficacy}

Capable students who are plagued by a loss of confidence in performing science-related tasks generally avoid science-related careers, which are on the rise in number and importance (National Science Board, 2010). Such students may close the doors to the personal challenges and fulfillment unique to careers in the sciences. Increasing the number of students who pursue careers in science and related fields is especially important at a time when the United States is seeing its standing as the dominant power in cutting edge science and technology rivaled (Thursby \& Thursby, 2006).

A wealth of research has shown that perceived academic efficacy plays an influential role in students' school success and in the academic choices they make (Schunk \& Pajares, 2005). Students' beliefs about their academic capabilities have been shown to influence their performance in a variety of academic subjects, their interest and effort, and their subsequent academic and career choices (see Pajares \& Urdan, 2006). In the domain of science, selfefficacy is related to middle and high school students' motivation and achievement (Britner \& Pajares, 2001, 2006; Kupermintz, 2002; Lau \& Roeser, 2002; Pajares, Britner, \& Valiante, 2000) and to college students' achievement and persistence in science-related majors and career choices (Andrew, 1998; Gwilliam \& Betz, 2001; Lent, Brown, \& Larkin, 1984; Luzzo, Hasper, Albert, Bibby, \& Martinelli, 1999).

A growing body of research has focused on how individuals form these important selfbeliefs. Bandura (1997) posited that self-efficacy is formed by how people interpret information from four sources. The most powerful source is the interpreted result of one's past performance, or mastery experience. As individuals engage in tasks and activities, they interpret the results from these experiences and form conceptions about how capable they are in engaging in 
subsequent related tasks and activities. Students who view their past accomplishments in a positive light are likely to experience a boost in their self-efficacy. Experiences viewed as unsuccessful are likely to have the opposite effect.

Self-efficacy is also influenced by the observation of others' activities. These vicarious experiences are thought to be most influential when individuals are uncertain of the standards by which proficiency in an activity is measured. Social models, particularly those individuals perceived as similar such as classmates, often act as a point of comparison as students form conceptions of their own academic capability (Schunk, 1983a, 1987). This is especially true during transitional periods, such as from elementary school to middle school, when students are more attuned to social comparative information (Eccles, Midgley, \& Adler, 1984).

A third source of self-efficacy comes from the verbal and social persuasions that individuals receive from influential others such as teachers, parents, and peers. Encouraging feedback and judgments bolster students' self-efficacy to perform a task, whereas deflating messages undermine it. Bandura (1986) argued that these deflating messages might actually be more effective in lowering self-efficacy than encouraging messages are at raising it.

The fourth hypothesized source comes from individuals' physiological and affective states such as anxiety, stress, and fatigue. Interpretations of these states often serve as indicators of students' competence (Bandura, 1997). Accordingly, students who view a heightened level of anxiety as threatening are generally less confident in their academic capabilities than are those who interpret these feelings as energizing.

Information conveyed through these four sources is not inherently informative. Rather, it must be selected, weighted, and incorporated into individuals' judgments of personal efficacy. For example, an elevated heart rate and shaky hands may be the main focus of one test taker's 
attention, to the point that they are debilitating, but for another student such physiological states may serve as an invigorating motivator. Therefore, information from each of the four sources exerts its influence on self-efficacy only after being cognitively processed by the individual.

Information from these sources of self-efficacy is almost always intertwined (Bandura, 1997). Students who thrive in school chemistry laboratories are also likely to earn good grades in chemistry class, receive verbal encouragements from their peers and teachers, and experience positive feelings toward chemistry-related activities. Students who do well in science are also likely to have influential role models who are proficient in science. The combined influence of information from these sources is likely to strengthen students' sense of efficacy in science.

Research on the sources of self-efficacy has confirmed the interrelatedness of efficacyrelevant information (see Usher \& Pajares, 2008, for a review). Nevertheless, researchers have primarily been interested in determining the relative potency of the four sources in relation to self-efficacy. This determination is typically made using a variable-centered approach in which the desired self-efficacy outcome is regressed on the four sources of efficacy information. Beta weights and statistical significance are then evaluated to determine the "strongest" source of selfefficacy (e.g., Britner \& Pajares, 2006; Lent, Lopez, \& Bieschke, 1991). Although useful, this methodological approach is limited in its ability to test the various combinations of efficacyrelevant information that students have reported.

Our primary goal in this study is to make use of a technique that will enable us to explore the different configurations of the sources of self-efficacy that arise among middle and high school students in the area of science and to examine how these profiles are related to students' self-efficacy in science. Latent profile analysis permits us to take a person-centered approach in which students' combined responses to items assessing the four sources of self-efficacy are used 
conjointly to create latent profiles or classes to which any given student is more likely to belong. We expand on this methodological approach below.

Our second point of interest in this study is to investigate individual differences related to the sources of self-efficacy profiles. Although researchers have devoted increasing attention to the sources of self-efficacy, few have attempted to investigate the ways in which students' preconceptions may bias the types of information to which they attend when evaluating what they can do. We therefore sought to determine how students' pre-existing beliefs might dispose them to interpret efficacy-relevant information in different ways. Bandura (1986) argued that individuals' preconceptions - their cognitive competencies and perceptual sets - affect the information to which they attend. In their review, Usher and Pajares (2008) likewise suggested that, "studies of the sources of self-efficacy will be enriched by attending to students' habits of thinking - their predispositions toward viewing the world and their preconceptions about school, learning, and their academic selves" (p. 40).

One preconception through which students may interpret their academic experiences is their implicit theory of ability - the view that people hold of ability as either a fixed entity or as a quality that can change with effort and appropriate strategies. According to Dweck and Leggett (1988), students who adopt an entity view of ability are more inclined to believe that abilities are relatively static characteristics that cannot be changed. Those who espouse an incremental view of ability are more likely to believe that abilities are changeable and thus within one's control. These implicit theories create a meaning system (Hong, Chiu, Dweck, Lin, \& Wan, 1999) in which ability and effort are given disproportionate weighting. Students with an incremental theory are apt to place more import on effort, whereas those with an entity theory tend to place more weight on ability. 
Although much research has investigated how implicit theories of ability operate within math classes, far less research has explored the construct within science classes. Yet, the implicit theory construct is likely useful for helping researchers and educators to better understand science motivation. Science is often construed as being more difficult than other subjects (see Dweck, 2007), and when students lose the desire to pursue science-related subjects, they often point to their perception that they lack the ability to do science (National Academies of Science, 2011).

In this study we propose that students' implicit theories of ability serve as a lens through which they interpret information from the four hypothesized sources of self-efficacy. How might people's conceptions of ability affect the processing of efficacy-relevant information? According to Bandura (1997), conceptions of ability exert their influence on self-regulatory mechanisms that govern cognitive functioning. In particular, conceptions of ability bias the ways in which failures are cognitively processed. For example, Wood and Bandura (1989) showed that conceptions of ability bias how substandard performances are processed within a business management setting. Participants who construed their poor performance as evidence of their personal deficiencies reported lower self-efficacy. On the other hand, those who framed their poor performance as a learning experience for self-improvement (i.e., an incremental view) suffered no loss of self-efficacy.

In another experiment, participants who were told that their ability to perform a motor task required an innate ability reported no change in self-efficacy for the task over a series of trials (Jourden, Bandura, \& Banfield, 1991). However, those who were induced to believe that they could improve in their ability to perform the task displayed a growth in self-efficacy. These studies suggest that conceptions of ability may be affecting how information from mastery 
experiences gets cognitively processed, thereby affecting people's judgments of personal efficacy.

How might conceptions of ability affect how students cognitively process information from vicarious experiences? Bandura (1997) again suggested that the influence of vicarious models on students' self-efficacy depends on whether students believe that the modeled skills can be developed. Empirical results in the stereotype threat literature support this contention (e.g., Bagès \& Martinot, 2012; Good, Aronson, \& Inzlicht, 2003; Thoman, White, Yamawaki, \& Koishi, 2008). Studies exploring which types of role models are most effective reveal that observers benefit most from role models whose accomplishments they perceive as attainable (Earley \& Kanfer, 1985; Lockwood \& Kunda, 1997; Lockwood, Jordan, \& Kunda, 2002). Given the results of these studies, it is likely that modeled performances (i.e., vicarious experiences) that are perceived to demonstrate cultivatable skills versus inborn gifts may be more influential in terms of changing learners' efficacy beliefs. Empirical evidence is needed to support this claim, however.

With regard to social persuasions, Schunk (1983b, 1984) has shown that students who hold a fixed view of ability reported lower self-efficacy when told that their progress was due to hard work. When their progress was attributed to innate ability, however, self-efficacy rose. Also, Cianci, Schaubroeck, and McGill (2010) showed that students who pursued a task to demonstrate their competence (performance goal) performed poorly on a task after negative feedback if they also espoused a fixed view of ability. However, students who held performance goals and who espoused an incremental view of ability improved their performance after negative feedback. Similar results indicating the moderating effect of implicit theories on academic outcomes have been shown (e.g., Butler, 2000). 
Dweck and her colleagues have also argued that implicit theories affect cognitive processing because of the meaning systems that they create (Dweck, 1999; Dweck \& Grant, 2008; Dweck \& Leggett, 1988; Dweck \& Master, 2009; Hong, Chiu, Dweck, Lin, \& Wan, 1999; Molden \& Dweck, 2006). In this social-cognitive framework, a fixed theory of ability and an incremental theory of ability create different motivational paths. These paths begin with students' conceptions of ability, which then create different reasons for pursuing tasks. In the fixed view of ability, students pursue tasks because they either want to prove to others (and themselves) that they are "smart" or they want to avoid appearing incompetent. However, those who espouse an incremental view of ability pursue tasks simply for the sake of learning. Because these two conceptions of ability set students up for very different goals (learning versus demonstrating/avoiding competence), it is possible that these two conceptions bias students' attention toward different types of information, as we describe below.

There has been some support for this hypothesis. For example, Mangels, Butterfield, Lamb, Good, \& Dweck, (2006), using Electroencephalograms (EEG waveforms), found that students with a fixed view of ability were more attentive to whether they answered a question correctly or not. However, they were less attentive to the feedback given. Students with an incremental theory of ability, however, paid attention to both the correctness of their answer as well as the feedback. These findings are in line with the hypothesis that implicit theories may serve as a filter through which efficacy-relevant information passes. In short, the ways in which students construe their ability as either fixed or malleable can subtly yet substantively color their perceived experiences, and, in turn, their self-view.

In addition to implicit theories of ability, other individual-level differences can influence the psychological processes at work as students develop their self-efficacy (Pajares, 2006). In 
this study we investigated the role of two such variables — students' gender and grade level—in terms of how they might be related to students' sources of self-efficacy profile. For example, researchers have reported that, although mastery experiences tend to be the most powerful predictor of self-efficacy, girls and women may place more emphasis on vicarious models and social persuasions (Britner, 2007; Zeldin, Britner, \& Pajares, 2008). Grade level may also play a role in the types of efficacy-relevant information to which students attend (Bandura, 1997). Although older students are able to handle more efficacy-relevant information cognitively, they may experience demotivating messages from their learning environment that lead to a decline in their self-efficacy (Bandura, 1997; Eccles \& Midgley, 1989; Eccles, Midgley, \& Adler, 1984).

\section{Research Questions and Hypotheses}

Given the objectives of the present study and the theoretical framework outlined above, the following research questions and hypotheses guided the study. First, we asked, what profiles of the sources of science self-efficacy emerge among the students in our sample? Based on Bandura's (1997) hypothesis that mastery experiences are the most influential source of selfefficacy and substantial empirical evidence showing the same (see Usher \& Pajares, 2009 for a review), we hypothesized that a profile exhibiting strong mastery experiences with less prominent vicarious experiences, social persuasions, and physiological/affective states would arise, and that this would be the largest profile (i.e., most students would fall into this category). We also hypothesized the existence of less common profiles constituting multiple prominent sources of self-efficacy. Finally, because science in the middle school and high school years is often a subject that causes much anxiety for students, we hypothesized a profile of students who report high scores for physiological/affective states (i.e., negative arousal towards science). 
We next asked, what is the relationship between the latent profiles and science selfefficacy and achievement? We hypothesized that profiles that reflect higher ratings of mastery experience, vicarious experience, social persuasions, and lower ratings of physiological states would have higher mean values of science self-efficacy and science achievement. This hypothesis is in keeping with social cognitive theory, which suggests that the hypothesized antecedents of self-efficacy should be related to the efficacy beliefs students hold and, by proxy, to behavioral outcomes such as achievement.

Last, we asked, what differences exist between each of the latent profiles as a function of implicit theory of ability, gender, and grade level? We hypothesized that students' implicit theories of ability act as "habits of thinking" that predispose them to perceive information about their academic capabilities differently (Usher \& Pajares, 2008, p. 790). We therefore expect to find a relationship between theories of ability and the sources of self-efficacy profiles. We hypothesized that girls would be more likely to be represented in profiles that are high in social persuasions, given past empirical evidence suggesting that girls tend to be more attuned to social messages, especially in science and math (Zeldin, Britner, \& Pajares, 2008; Zeldin \& Pajares, 2000). With regard to grade level, we foresaw two possibilities. First, because older students are able to cognitively process more information from diverse sources (Bandura, 1997), they may be more likely to be represented in profiles where two or more sources are used prominently. Second, we hypothesized that the higher-stakes assessments in the upper grades and the increasing rigor of science content would make it more likely for older students to be represented in profiles that display higher levels of negative physiological arousal (i.e., higher scores on physiological/affective states).

\section{Method}




\section{Participants and Setting}

Participants $(N=1,225)$ included 454 high school science students attending a regular public high school in the Southeastern United States; 263 high school science students attending a charter school (in the same county as the regular public school) whose curriculum was specifically focused on Science, Technology, Engineering, and Mathematics (STEM) ${ }^{1}$; and 508 middle school students. Table 1 provides more information on student demographic information (e.g., gender, ethnicity, free/reduced-priced lunch status, gifted status, and grade level) for the full sample and by school.

Only students in Grades 6, 9, and 10 were surveyed due to timing constraints that limited the research team's access to all grade levels, although 26 students (2.1\%) were in Grades 11 and 12. Grade 6 science students in this school studied Earth Science, which introduces students to topics such as astronomy, meteorology, and geology. Grade 9 students in the regular public school were enrolled in biology (either at the gifted, honors, or college preparatory level. Gifted level is the highest ability group and college preparatory is the lowest ability group). Grade 10 students were enrolled in chemistry. At the charter school, Grade 9 students took two science courses - physics and chemistry. Students then chose one of the following courses: "Engineering Applications" or "Intermediate Computer Programming," both of which were also year-long courses. Grade 10 students took a year-long Biology course, a year-long engineering course, and a year-long Calculus course.

The instrument was group administered in the participants' science classes. Students were told that the purpose of the study was to obtain their opinions about science class and about themselves as science students. They were informed that the results of the survey would be kept confidential. The Likert-type scale was explained and students were guided through the first 
items to ensure that they knew how to respond using this type of scale. They were encouraged to ask questions as they arose. Survey administrators were instructed to answer questions about the meanings of words or phrases that were unfamiliar to the students and, when necessary, to paraphrase items without changing their meaning.

\section{Data Sources}

Sources of self-efficacy. The four sources of self-efficacy were assessed using a scale adapted from work previously done with middle school mathematics students (Usher \& Pajares, 2009). For the present study, these items were reworded for the domain of science. The items from this recently-validated scale are conceptually and psychometrically stronger than items previously used in studies of the sources of self-efficacy (e.g., Britner \& Pajares, 2006). Six items addressed mastery experiences (e.g., "I have always been successful with science”), six addressed vicarious experiences (e.g., "Seeing adults do well in science pushes me to do better"), six items assessed social persuasions (e.g., "People have told me that I have a talent for science"), and six items assessed physiological state (e.g., "Just being in science class makes me feel stressed and nervous"). Three of the six items assessing vicarious experiences in the original scale that was validated by Usher and Pajares were replaced with three vicarious experience items from the Usher and Pajares (2006) scale. These items were the following: "Many of the adults I know have jobs that involve science;" "People I admire are good at science;" and "The people I want to be like are mostly people who are involved in science." We included these three items because they seemed to tap social modeling in the domain of science in ways that are not as relevant in mathematics, a field in which there may be fewer career role models. Cronbach's alpha coefficients were .87 for mastery experience items, .71 for vicarious experience items, .85 for social persuasions items, and .86 for psychological and affective state items. 
Science self-efficacy. Science Self-Efficacy was assessed with four items that asked participants to rate how confident they were that they could earn a particular grade (i.e., A, B, C, or D) in their science class at the end of term (e.g., "How confident are you that you will get a grade of "C" or better in science this semester?"). This scale follows Bandura's (2006) guidelines for constructing self-efficacy scales. Researchers who have used this scale have obtained coefficient alphas ranging from .85 to .91 (e.g., Britner \& Pajares, 2001, 2006; Pajares et al., 2000). We obtained an alpha coefficient of .83 .

Implicit theory of ability. Implicit theory of ability was assessed with a six-item measure developed by Dweck (1999). Items were worded for the domain of science, as individuals' implicit theories of ability are likely to be domain specific (e.g., some students may believe that their science ability is a relatively stable entity but that their abilities in social studies are increasable; Stipek \& Gralinsky, 1996). Three items assessed students' fixed theory of science ability (e.g., "You have a certain amount of science ability, and you really can't do much to change it") and three assessed their incremental theory (e.g., "No matter who you are, you can change your science abilities a lot"). The items assessing fixed ability were reverse scored and a mean implicit theory of ability score was calculated. Higher scores on the scale indicated a more incremental view of science ability and lower scores represented a more fixed view. Cronbach's alpha for the items was .81 .

\section{Analysis}

The theoretical framework that undergirds this person-centered analysis assumes that individuals are capable of holding multiple beliefs. A number of methods enable researchers to analyze data from a person-centered perspective (e.g., median splits and cluster analysis). We employed Latent Profile Analysis (LPA) in the present study. LPA is a latent variable mixture 
modeling technique used to identify groups of individuals that have similar values on the clustering variables, also called latent class indicators. In this study, the latent class indicators were the four sources of self-efficacy. All analyses were performed using Mplus 6 (Muthén \& Muthén, 2010).

For the first research question, we were interested in patterns of beliefs (i.e., about efficacy-relevant experiences) among students in science classes. For this reason, we employed a method of analysis that forms homogenous groups of students. In uncovering the number of latent classes or profiles that emerge from the data, we fit the data to models with 2 through 6 latent classes $(k=2-6)$. We decided to examine solutions with no more than 6 latent classes because attempts to use 7 latent classes resulted in model convergence problems, suggesting that 7-class models do not fit the data well. As we describe more fully in the next section, we chose a 4-class solution as the best representation of our data based on a number of fit indexes.

The fit index we used was the Lo-Mendell-Rubin Likelihood Ratio Test (LMR; Lo, Mendell, \& Rubin, 2001). The LMR helped determine the number of groups that fit the data the best. $P$ values were used to determine statistical significance of accepting the model with $k$ groups over the model with $k$ - 1 groups. We also based our decision on the Bayesian Information Criterion (BIC), for which lower values indicate better fit (Henson, Reise, \& Kim, 2007; Magidson \& Vermunt, 2004). Although the Bootstrap Likelihood Ratio Test (BLRT; McLachlan \& Peel, 2000) has been viewed by some as superior to the LMR in deciding on the number of latent profiles (Nylund, Asparouhov, \& Muthén, 2007), the BLRT was not useful in our investigation because all analyses produced a $p$ value of $<.0001$ and were therefore not trustworthy. This resulted despite the recommendation to use 40 draws for the model with $k$ classes in the initial stage followed by 10 optimizations in the final stage (Muthén \& Muthén, 
2010). Problems with the BLRT have been recently reported in mixture model analyses (e.g., Li \& Hser, 2011). For these reasons, we did not report BLRT $p$ values.

We used two models in the present study (see Figure 1). Model 1 was used to answer Question 1, and Model 2 was used to answer Question 3. In Model 1, c represents the four latent groups that arose from the data, and $\mu$ represents each of the four sources of self-efficacy. The arrows drawn from $c$ to $\mu$ indicate that the means of the sources of self-efficacy freely vary across the classes of $c$. Within-class means and variances of the observed variables were estimated. Covariances between the indicators were constrained to zero. As illustrated by Marsh, Ludtke, Trautwein, and Morin (2009), this parameterization represents Classic LPA, where there is an assumption of local independence. Best practices, according to Marsh et al., dictate that this assumption of conditional independence not be relaxed unless special a priori circumstances call for it. Therefore, the conditional independence assumption was not relaxed for our analyses.

Question 2 examined the relationship between the emergent latent profiles and science self-efficacy and achievement. Mplus 6 offers a function called AUXILIARY (e), which tests for the equality of means using additional variables of interest (i.e., that were not used in forming the latent profiles). This procedure employs a Wald chi-square test statistic to examine whether there is a statistically significant difference in the mean self-efficacy and achievement levels across sources of self-efficacy profiles. We calculated Cohen's $d$ using pooled standard deviations to determine effect sizes for these differences. In cluster analysis, students are placed in discrete clusters or profiles. LPA, however, accounts for the uncertainty of whether someone belongs in one group by assigning a probability that a student is in one profile as opposed to another. These uncertainties are generated by Mplus as posterior probabilities, which are then 
used in calculating the Wald chi-square statistic for equality of means. Performing this procedure is a way to explore the mean differences in self-efficacy and achievement among the latent profiles that emerge.

Finally, to explore how the emergent student profiles differ by implicit theory of ability, gender, and grade level, we included these latter variables in the model as covariates that predicted latent class membership. This is illustrated as Model 2 in Figure 1. To do this, we first employed Mplus's AUXILIARY (r) function, which uses variables that were not used in forming the profiles to identify covariates that might be important predictors of the latent classes. This is done by using pseudo-class draws, which are the posterior-probability-based multinomial logistic regressions of a categorical latent variable (latent class) on a set of covariates.

After determining which of the above factors were significant predictors of latent class membership, we included in the model those variables that significantly predicted membership by regressing the categorical latent variable (latent class) on the covariates. Marsh et al. (2009) suggested that correlates should not be included in the model if they influence the definition of the latent groups. Therefore, after including the covariates, we used fit indexes to choose the best fitting model (with $k=2$ to $k=6$ classes) and compared that model to the original model without covariates. Substantive differences that arose between these two models would suggest that the correlates should not be included.

In addition, Marsh et al. (2009) strongly recommended that covariates be included in a model only if there is sufficient evidence to assume that the covariates are antecedent variables. For the present study, implicit theory of ability, gender, and grade level were assumed to influence the way in which students are categorized into each profile. Implicit theories of ability serve as core assumptions that foster a framework for viewing information from a particular 
domain (Dweck, Chiu, \& Hong, 1995; Dweck \& Leggett, 1998). Thus, it seems reasonable to assume that implicit theories serve as a lens through which efficacy-relevant information gets interpreted, which in turn relates to how students are categorized into profiles. As has been shown previously, demographic variables such as gender and age (grade level, in this case) are appropriate to include as covariates (Muthén, 2006).

\section{Results}

The primary aim of this study was to apply a novel analytic method to enhance understanding of how the sources of self-efficacy operate in the domain of science. We first sought to identify the patterns by which students responded to the sources of science selfefficacy, and to see how these emergent profiles related to science self-efficacy and achievement. Table 2 shows the fit statistics for each of the models tested. Although there is no consensus about "golden rules" for determining the number of classes to choose, we followed recommended practices to arrive at the final solution, such as considering both a goodness of fit index and a test of significance (Masyn, in press). We used the difference in LRT, as developed by Lo, Mendell, and Rubin (2001), and the Baysian Information Criterion (BIC). To help determine how many groups best fit the data, we created a plot of the BIC versus the number of classes to produce a graph similar to a scree plot in exploratory factor analysis. This is an initial way to evaluate how many latent classes may be appropriate, with a good fitting solution being the one in which an "elbow" appears in the graph to signal that additional classes do not significantly reduce the BIC. This plot showed that an elbow was formed at the 4-class model, indicating that there was no significant improvement of the BIC beyond a model with four categories. The LMR likelihood ratio test (Lo et al., 2001) produced a nonsignificant $p$ value at the 5-class solution, suggesting that the 5-class model did not provide a statistically significant 
improvement in fit. Based on these fit indexes and interpretability, we decided on the more parsimonious 4-class model.

Also, because issues about the reliability of profiles are an important concern, the entire sample of middle and high school students was split in three different ways: 1) by random splithalves, 2) by grade level, and 3) by each individual school. When compared to the full 1225student sample, similar patterns were uncovered, thus providing evidence for the reliability of the groups. Therefore, considering the fit indexes, interpretability, and theory as guides, a 4-class model was chosen. As illustrated next, the profiles were differentiated by their levels of selfefficacy and their science achievement, thereby lending evidence for the validity of these profiles.

Figure 2 illustrates the four latent profiles, which are labeled according to our interpretation of findings. Pairwise comparisons revealed that self-efficacy and achievement levels were significantly different $(p<.05)$ for students in each of these profiles. The MultiSource group was named as such because students in this group seemed to be attentive to multiple sources of self-efficacy rather than just one or two. These students were characterized by strong mastery experiences $(M=5.38)$, vicarious experiences $(M=4.57)$, and social persuasions $(M=4.96)$, along with low physiological and affective arousal $(M=1.58)$. At 247 students (20.2\%), this was the smallest group in the sample. As Figure 3 illustrates, these students reported the highest science self-efficacy $(M=5.62)$ and received the highest science grades $(M=89.4)$. The Mastery group was named as such because these students seemed to derive their sense of efficacy almost exclusively from mastery experiences. This profile was characterized by its high reports of mastery experiences $(M=4.97)$ in science class and relatively low reports of vicarious experiences $(M=3.12)$ and social persuasions $(M=3.47)$. This group 
of students also reported low adverse physiological responses $(M=1.65)$. When compared to the Multi-Source group, students in the Mastery group reported significantly lower science selfefficacy $(M=5.46 ; p<.001, d=.78)$ and achievement $(M=83.2 ; p<.001, d=.63)$.

The distinguishing characteristic of the At Risk group was their significantly higher (i.e., more adverse) physiological and affective responses compared with any other group $(M=3.40)$. Because elevated levels of negative physiological and affective responses are typically associated with negative academic outcomes, we labeled the students in this profile as At Risk. These students also reported fewer mastery experiences $(M=2.99)$, vicarious experiences $(M=$ 2.67), and social persuasions $(M=2.12)$. With regard to science motivation, these students reported significantly lower self-efficacy $(M=3.50)$ than did any other group $(p<.001, d$ ranged from .86 to 1.6). At the end of the term, these students also received the lowest science grade compared with their peers $(M=74.4 ; p<.001 ; d$ ranged from .55 to 1.2$)$. This profile represented the second largest group of our sample $(n=340 ; 27.8 \%)$.

Finally, students in the largest group of the sample $(n=357 ; 29.1 \%)$ reported fairly Moderate responses for the four sources and for science self-efficacy. No particular source of self-efficacy stood out in the profile. At the end of the term, these students earned a final average science grade of 83.2 .

Our second objective was to examine whether there were individual differences among students in each of these latent profiles. After testing the fit of the 4-class model, we added covariates simultaneously (implicit theory, gender, and grade level), assessed the fit of the revised model, and determined whether there were any differences in how the profiles were formed with the covariates included. Significant changes in how the profiles are formed would indicate that adding the covariates is inappropriate for this particular model. Our results showed 
that there were no major differences in the two solutions. All profiles were reproduced in a similar fashion. The only change we noticed was that the Mastery group decreased in number when including the covariates ( $n=280$ in Model 1 to $n=230$ in Model 2), and the Multi-Source group increased slightly in number $(n=247$ in Model 1 to $n=260$ in Model 2). The Mastery group therefore became the smallest group in the model with covariates.

Students' implicit theory of ability and grade level were significant predictors of their membership in a latent class $(p<.05)$. Gender was not a statistically significant predictor of class membership and was therefore removed as a covariate from Model 2. Table 2 shows the probabilities of being in a particular latent class as a function of implicit theory of ability and grade level, and Figures 4 and 5 illustrate the relationships graphically. We calculated the probability that a student would be classified in a particular profile given that the student's selfreported implicit theory score was at the mean value (4.4), one standard deviation below that mean (i.e., reflecting a more fixed theory of ability), and one standard deviation above that mean (i.e., reflecting a more incremental theory of ability). For grade level, we calculated probability values for those students in Grades 6, 9, and 10, as they represented almost all (97.9\%) of the students in the study.

We found that students who held stronger views about the incremental nature of science ability were more likely to be in the Multi-Source group than were their peers who espoused a more fixed view of science ability. Students who reported more incremental views of ability were also less likely to be in the At Risk group. Grade level was held constant in these analyses. In terms of grade level, students in higher grade levels were less likely to be in the Multi-Source group but were more likely to be in the At Risk group, compared with their younger peers, holding implicit theory constant. 


\section{Discussion}

The first goal of this study was to examine the patterns, or profiles, of the sources of science self-efficacy reported by middle school and high school students and to determine the relationship between these patterns, self-efficacy, and achievement. The second goal of the study was to investigate whether students' sources profiles could be predicted by the preconceptions students hold about the nature of ability in science, students' gender, or their grade level. Below we discuss each of the four profiles that emerged from students' reported exposure to sources of self-efficacy information in order of what we have deemed to be most to least adaptive. In each section we discuss findings in terms of our three research questions.

\section{Multi-Source Profile}

As hypothesized, we found a profile of students who tend to rely on multiple sources of efficacy information in science. These students reported more favorable levels of the four sources of efficacy information than did students in any other profile as well as the highest mastery experiences. They were also most confident in their science capabilities and achieved higher in science than did their peers in any other group. These Multi-Source students appear to be most adaptive in their self-efficacy profile.

Bandura (1997) noted that the rules individuals use when weighting and integrating information about their efficacy from diverse sources may affect how self-efficacy develops. In the case of this adaptive profile, it seems that an additive effect of relying on all sources of efficacy information, and having numerous mastery experiences in science, might have led to the highest level of self-efficacy in science. These results also lend support to Bandura's (1997) assertion that mastery experiences are the most influential source of self-efficacy. The Multi- 
Source profile accounted for only one-fifth of the students in our sample, however, which indicates that most students experience efficacy-relevant information in other configurations.

Our findings also support the hypothesis that one's implicit theory of ability may serve as a filter through which efficacy-relevant information is processed, and as a result, influence one's self-efficacy. Students who espoused a stronger view that science ability can be improved with effort were more likely of being in the most adaptive, Multi-Source group. It may be that students who espouse an incremental view of ability tend not to get caught up in non-salient ability information such as negative affect and distractions while working on a task, which has been found by other researchers (e.g., Da Fonseca et al., 2008; Dweck \& Leggett, 1988).

Our results also suggest that, although older students are cognitively more able to handle diverse efficacy-relevant information, the upper grade-level students in our sample were less likely to be a member of this Multi-Source profile than were their younger peers. This suggests that students' developmental status in school may be related to how students differentially weigh the various types of efficacy information. Longitudinal research designs would help researchers trace changes in the importance students place on the sources of self-efficacy as they progress through school.

\section{Mastery Profile}

Also as hypothesized, we found one profile of students who tend to rate mastery experiences higher than they do information from other sources of self-efficacy. Students in this group reported the second highest science self-efficacy among groups (though still significantly lower than that of students in the Multi-Source group). Mastery experiences are salient for many individuals and may be a primary source of self-efficacy for some students (Bandura, 1997). However, relying on other sources of self-efficacy in addition to mastery experience seems to 
carry an added benefit to students' self-efficacy and achievement. Although students in this Mastery profile have obviously experienced success in science, they may not have been as attentive to (or exposed to) information from the other sources. We hypothesized that the most prominent group to arise would be the Mastery profile, given that Bandura (1997) described mastery experiences to be the most powerful and salient type of efficacy-relevant information. However, the Mastery group and the Multi-Source group were the smallest profiles of the sample. Bandura's contention that mastery experiences are the strongest source of self-efficacy likely refers to the strength with which this particular source predicts self-efficacy. Indeed, researchers who have investigated the relative influence of the four types of efficacy information on self-efficacy have reported that the effect size for mastery experiences is considerably larger than the effect of any other source (e.g., Britner \& Pajares, 2001, 2006; and see Usher \& Pajares, 2008, for a review). Our findings demonstrate the strength of this source's influence does not necessarily correspond to the number of students who attend most strongly to mastery experiences.

The probability of being in this Mastery profile increased for students who believed that their science ability could be cultivated, suggesting that an incremental view of ability is consistent with perceived past successes in science. With regard to group differences, we did find that students in higher grade levels were much less likely than their younger peers to belong to this Mastery profile. Once again, this finding indicates fewer perceived mastery experiences in the upper grades and a greater risk for maladaptive self-efficacy and lower achievement for older students. Although we did not examine teaching practices in the present study, our findings imply that secondary students' self-efficacy could be improved by more frequent opportunities for mastery of science content. 


\section{Moderate Profile}

Compared to their peers, students in this profile did not exhibit any distinguishing patterns in how the sources of their self-efficacy configured. One possibility is that these students were in fact somewhat unsure of whether they experienced past successes, had competent models to observe, received positive messages from others, or felt anxious about science. Another explanation lies in the nature of the analysis. Although LPA is a technique that categorizes students based on how similarly they respond, the technique still relies on an averaging process. Given that this group is the largest of all the groups, it is possible that using a calculated mean of all students in the profile masks the amount of variation that exists between students. However, based on the moderate ratings that these students reported on self-efficacy and their moderate levels of science achievement, it is likely that these students were in fact quite average with respect to their beliefs and achievement. This is further supported by the unsubstantial changes in probability of being in the group as a function of implicit theory of ability.

\section{At Risk Profile}

In the second-largest profile of the study were students who reported little exposure to efficacy-building information. Compared to those in other groups, students in this At Risk profile experienced fewer successes in science, less exposure to competent models, fewer positive messages about their science capabilities, and notably more anxiety and stress related to their science classes. These students had significantly lower self-efficacy and achievement than did their peers in other profiles.

We found that students who believed that ability in science is an innate trait were far more likely to be in the At Risk group as compared to their peers who held a more incremental 
theory of science ability. This relationship indicates that the probability of being in the At Risk group drops substantially when individuals tend toward a view that science ability is something that can be cultivated with effort. This finding illustrates how salient negative physiological and affective information can be when students operate under the belief that they cannot do anything to change their inherent science abilities. This result is consistent with research in other domains that has revealed a connection between a fixed implicit theory of ability and anxiety (e.g., Da Fonseca et al., 2008) or other forms of negative affect (Dweck \& Leggett, 1988).

Bandura (1997) has argued that people are generally poor at integrating information from multiple sources. When faced with diverse information, individuals attend more to information that comes to mind most readily, overlooking more distal information that is less immediately accessible. Individuals who espouse a fixed view of ability may be especially prone to attending to fewer pieces of information (Dweck, 1999; Dweck et al., 1995). Our findings show that students in the At Risk profile attended more to negative affect in science and reported low levels of the other three sources of self-efficacy, which were positively framed. Students who believe that there is nothing that they can do about their science abilities may view their science experiences through a lens that filters out more adaptive types of efficacy-relevant information. Bandura (1997) contended that physiological and affective states become more potent when fewer indicators of one's efficacy are present (e.g., mastery experiences). The At Risk students in our sample reported very few efficacy-building experiences, which may explain why anxiety and depressive moods played a primary role in how students judged their own efficacy in science. On the other hand, the Multi-Source students reported low levels of negative physiological and affective arousal, likely because of the high level of salient efficacy-relevant 
information that they had experienced. A person-centered analysis makes it easier for researchers to see this pattern.

The implication of these findings for educators is that one good way to counteract the negative effects of anxiety is to build students' self-efficacy by exposing them to information from the other three sources. Building individuals' self-efficacy through mastery experiences alone can dramatically reduce the negative construal of anxiety and stress (Bandura, 1997). Some may be tempted to think that an obvious solution is to enhance student motivation and achievement performance via stress-reduction techniques. Bandura warned about such an approach: "Anxiety is best allayed not by anxiety palliatives but by building a strong sense of efficacy through development of cognitive capabilities and generalizable self-regulatory skills for managing academic task demands, self-debilitating thought patterns, and aversive affective states" (p. 236). That is, to maximize gains in student self-efficacy, teachers should provide ample opportunities for academic and metacognitive skill development (e.g., frequent mastery; better strategies for goal setting, studying, self-reflection), especially for these At Risk students.

Changes in how science is taught and assessed during students' adolescent years, as opposed to their elementary school years, may account for why older students were more likely to be members of this At Risk profile. Many high schools and middle schools have structures in place (e.g., tracking levels, high student to teacher ratios, high-stakes tests) that thwart rather than cultivate students' belief in their capability to succeed (Grubbs \& Oakes, 2007). As students progress through school, they transition from a learning environment in which there is a wealth of efficacy-confirming information to one in which they tend to receive little individual attention and feedback, to be anxious about their performance on high-stakes tests, and to compare themselves to the relative ability levels of others (Barber \& Olsen, 2004). The 
complexity of science content and the requisite skills needed to succeed in science at higher levels (e.g., mathematical knowledge, problem-solving capabilities) might also lead to greater variation in performance, and, thus, in the challenges to which learners are exposed.

The emergence of this At Risk group does, however, offer a window of opportunity for the implementation of systemic changes and pedagogical and assessment approaches that can enhance students' competence and confidence. The Institute of Advanced Study's Commission on Mathematics and Science Education (2009) noted that teachers need access to the support and resources necessary for them to develop customized approaches to science instruction. This likely requires using technologies that give students accurate and timely feedback on coursework and formative assessments, provides teachers with information for how they can help their students, and provides students with the necessary scaffolds that lead to mastery.

\section{Conclusion and Limitations}

This study and its findings are limited in several ways worth noting. First, our findings could reflect a response set among participants that artificially places them in one sources of selfefficacy profile over another. For example, it is plausible that students in the Multi-Source profile tend to respond in the extreme to all self-report measures. The fact that these students also scored highest in science achievement, however, suggests that there is some relationship between internal, self-report tendencies and external measures. Still, alternative approaches such as item-response theory could be used to address the question of a possible response set bias. Also, as mentioned earlier, the present data were collected at one time point. Therefore, inferences about developmental changes from middle school to high school should be made with caution. Future research could apply longitudinal mixture models to explore how students transition from one profile to another over time. 
Also, the achievement data that were collected came in the form of end-of-year course grades, which are issued by teachers. We did not collect standardized test scores. Given the inherent subjectivity and variability in grading practices between teachers, future research should explore how results from the present study compare when using more objective measures of achievement such as standardized test scores in science.

We also recognize that the wording of the sources items could play a role in how students weigh and interpret information about their capabilities. For example, positively-worded mastery experience items invite students to report their successes but do not glean information about their perceived failures and setbacks in science, which may influence their self-efficacy in distinct ways. This question of valence in sources of self-efficacy measures has been a limitation noted by other researchers (Usher \& Pajares, 2008). Future work might investigate whether the sources profiles differ when the subscales used to assess efficacy-relevant information include events that may have lowered students' perceived efficacy (e.g., criticism from others).

These limitations notwithstanding, findings from the present study suggest that science teachers might focus their attention on providing students with instructional activities that provide a high probability of initial success, and then to carefully increase the difficulty of these tasks such that students can develop their skills and their confidence in being able to accomplish these increasingly more difficult challenges. Because mastery experiences have been shown to be the most influential source of self-efficacy, this approach appears to be the most likely to bolster students' motivation and achievement, especially as students progress into higher grade levels. The present study also suggests that implicit theories of ability might play an important role in how efficacy-relevant information is processed. Teachers would do well to cultivate a 
growth mindset in their students, as such an outlook appears to be associated with an adaptive interpretation of information related to one's self-efficacy.

A person-centered approach to investigating the sources of self-efficacy enables researchers to account for multiple sources of information when considering how self-efficacy develops. We found no evidence that students' gender is related to how they interpret information about their science capabilities. We are encouraged by this finding but believe that replication of these methods in other academic domains, such as those in which gender differences are historically observed (e.g., mathematics) is an important next step. Using qualitative methods to complement these quantitative findings, such as interviewing a subset of students in each latent profile group, would provide a richer description of how efficacy information is integrated and weighed by students in science. 


\section{References}

Andrew, S. (1998). Self-efficacy as a predictor of academic performance in science. Journal of Advanced Nursing, 27, 596-603.

Bagès, C. \& Martinot, D. (2012). What is the best model for girls and boys faced with a standardized mathematics evaluation situation: A hardworking role model or a gifted role model? British Journal of Social Psychology, 50, 536-543. doi: 10.1111/j.20448309.2010.02017.x.

Bandura, A. (1986). Social cognitive theory of human development. In T. Husen \& T. N. Postlethwaite (Eds.), International encyclopedia of education (2nd ed., pp. 5513-5518). Oxford: Pergamon Press.

Bandura, A. (1997). Self-efficacy: The exercise of control. New York: Freeman.

Bandura, A. (2006). Guide for constructing self-efficacy scales. In F. Pajares \& T. Urdan (Eds.), Adolescence and Education: Vol. 5. Self-Efficacy Beliefs of Adolescents (pp. 307-337). Greenwich, CT: Information Age.

Barber, B. K., \& Olsen, J. A. (2004). Assessing the transitions to middle and high school. Journal of Adolescent Research, 19, 3-30.

Britner, S. L. (2007). Motivation in high school science students: A comparison of gender differences in life, physical, and Earth science classes. Journal of Research in Science Teaching, 45, 955-970.

Britner, S. L., \& Pajares, F. (2001). Self-efficacy beliefs, race, and gender in middle school science. Journal of Women and Minorities in Science and Engineering, 7, 271-285. 
Britner, S. L., \& Pajares, F. (2006). Sources of science self-efficacy beliefs of middle school students. Journal for Research in Science Teaching, 43, 485-499.

Butler, R. (2000). Making judgments about ability: The role of implicit theories of ability in moderating inferences from temporal and social comparison information. Journal of Personality and Social Psychology, 78, 965-978.

Cianci, A. M., Schaubroeck, J. M., \& McGill, G. A. (2010). Achievement goals, feedback, and task performance. Human Performance, 23, 131-154.

Commission on Mathematics and Science Education (U.S.) (2009). Opportunity Equation: Transforming mathematics and science education for citizenship and the global economy. New York: Carnegie Corporation of New York.

Da Fonseca, D., Cury, F., Fakra, E., Rufo, M., Poinso, F., Bounoua, L., \& Huguet, P. (2008). Implicit theories of intelligence and IQ test performance in adolescents with Generalized Anxiety Disorder. Behaviour Research and Therapy, 46, 529-536.

Dweck, C. S. (Ed.). (1999). Self-theories: Their role in motivation, personality, and development. Philadelphia: Psychology Press.

Dweck, C. S. (2007). Is math a gift? Beliefs that put females at risk. In S. J. Ceci \& W. M. Williams (Eds.), Why aren't more women in science? Top researchers debate the evidence (pp. 47-55). Washington, DC: American Psychological Association.

Dweck, C. S., Chiu, C. Y., \& Hong, Y. Y. (1995). Implicit theories and their role in judgments and reactions: A world from two perspectives. Psychological Inquiry, 6, 267-285.

Dweck, C. S., \& Grant, H. (2008). Self-theories, goals, and meaning. In J. Shah (Ed.), Handbook of motivation science (pp. 405-416). New York: The Guilford Press. 
Dweck, C. S., \& Leggett, E. L. (1988). A social cognitive approach to motivation and personality. Psychological Review, 95, 256-273.

Dweck, C. S., \& Master, A. (2009). Self-theories motivate self-regulated learning. In D. H. Schunk \& B. J. Zimmerman (Eds.), Motivation and self-regulated learning: Theory, research, and applications (pp. 31-51). New York: Taylor \& Francis.

Earley, P. C., Kanfer, R. (1985). The influence of component participation and role models on goal acceptance, goal satisfaction, and performance. Organizational Behavior and Human Decision Processes, 36, 378-390.

Eccles, J. S., \& Midgley, C. (1989). Stage-environment fit: Developmentally appropriate classrooms for young adolescents. In C. Ames \& R. Ames (Eds.), Research on motivation in education (Vol. 3, pp. 139-186). San Diego: Academic Press.

Eccles, J. S., Midgley, C., \& Adler, T. (1984). Grade-related changes in the school environment: Effects on achievement motivation. In J. Nicholls (Ed.), Advances in motivation and achievement: The development of achievement motivation (Vol. 3, pp. 283-331). Greenwich, CT: JAI Press.

Good, C., Aronson, J., \& Inzlicht, M. (2003). Improving adolescents'standardized test performance: An intervention to reduce the effects of stereotype threat. Applied Developmental Psychology, 24, 645-662.

Grubbs, W. N., \& Oakes, J. (2007, October). Restoring value to the high school diploma: The rhetoric and practice of higher standards. Boulder, CO: National Education Policy Center. Retrieved from http://nepc.colorado.edu/publication/restoring-value-high-schooldiploma-the-rhetoric-and-practice-higher-standards. 
Gwilliam, L. R., \& Betz, N. E. (2001). Validity of measures of math- and science-related selfefficacy for African Americans and European Americans. Journal of Career Assessment, 9, 261-281.

Henson, J. M., Reise, S. P., \& Kim, K. H. (2007). Detecting mixtures from structural model differences using latent variable mixture modeling: A comparison of relative model fit statistics. Structural Equation Modeling, 14, 202-226.

Hong, Y. Y., Chiu, C. Y., Dweck, C. S., Lin, D. M. S., \& Wan, W. (1999). Implicit theories, attributions, and coping: A meaning system approach. Journal of Personality and Social Psychology, 77, 588-599.

Jourden, F. J., Bandura, A., \& Banfield, J. T. (1991). The impact of conceptions of ability on self-regulatory factors and motor skill acquisition Journal of Sport \& Exercise Psychology, 13, 213-226.

Kupermintz, H. (2002). Affective and conative factors as aptitude resources in high school science achievement. Educational Assessment, 8, 123-137.

Lau, S., \& Roeser, R.W. (2002). Cognitive abilities and motivational processes in high school students' situational engagement and achievement in science. Educational Assessment, 8, $139-162$.

Lent, R. W., Brown, S. D., \& Larkin, K. C. (1984). Relation of self-efficacy expectations to academic achievement and persistence. Journal of Counseling Psychology, 31, 356-362.

Lent, R. W., Lopez, F. G., \& Bieschke, K. J. (1991). Mathematics self-efficacy: Sources and relation to science-based career choice. Journal of Counseling Psychology, 38, 424-30. 
Li, L., \& Hser, Y. (2011). On inclusion of covariates for class enumeration of growth mixture models. Multivariate Behavioral Research, 46, 266-302. doi: 10.1080/00273171.2011.556549.

Lo, Y., Mendell, N., \& Rubin, D. B. (2001). Testing the number of components in a normal mixture. Biometrika, 88, 767-778.

Lockwood, P., Jordan, C. H., \& Kunda, Z. (2002). Motivation by positive or negative role models: Regulatory focus determines who will best inspire us. Journal of Personality and Social Psychology, 83, 854-864.

Lockwood, P., \& Kunda, Z. (1997). Superstars and me: Predicting the impact of role models on the self. Journal of Personality and Social Psychology, 73, 91-103.

Luzzo, D. A., Hasper, P., Albert, K. A., Bibby, M. A., \& Martinelli, E. A., Jr. (1999). Effects of self-efficacy-enhancing interventions on the mathematics/science self-efficacy and career interests, goals, and actions of career undecided college students. Journal of Counseling Psychology, 46, 233-243.

Magidson, J., \& Vermunt, J. (2004). Latent class models. In D. Kaplan (Ed.), Handbook of quantitative methodology for the social sciences (pp. 175-198). Newbury Park, CA: Sage.

Mangels, J. A., Butterfield, B., Lamb, J., Good, C. D., \& Dweck, C. S. (2006). Why do beliefs about intelligence influence learning success? A social-cognitive neuroscience model. Social, Cognitive, and Affective Neuroscience, 1, 75-86.

Marsh, H. W., Ludtke, O., Trautwein, U., \& Morin, A. J. (2009). Classical latent profile analysis of academic self-concept dimensions: Synergy of person- and variable-centered 
approaches to theoretical models of self-concept. Structural Equation Modeling, 16, 191225.

Masyn, K. E. (in press). Latent class analysis and finite mixture modeling. In T. Little (Ed.), Oxford Handbook of Quantitative Methods. Oxford: Oxford University Press.

McLachlan, G. \& Peel, D. (2000). Finite Mixture Models. New York: Wiley.

Muthén, B. O. (2006). Should substance use disorders be considered as categorical or dimensional? Addiction, 101(Suppl. 1), 6-16.

Muthén, L. K., \& Muthén, B. O. (2010). Mplus user's guide: Sixth edition. Los Angeles, CA: Authors.

Nylund, K. L., Asparouhov, T., \& Muthén, B. O. (2007). Deciding on the number of classes in latent class analysis and growth mixture modeling: A Monte Carlo simulation study. Structural Equation Modeling: A Multidisciplinary Journal, 14, 535-569.

National Science Board. (2010, May 10). Preparing the next generation of STEM innovators: Identifying and developing our nation's human capital. Downloaded on March 20, 2012 from www.nsf.gov/nsb/publications

Pajares, F. (2006). Self-efficacy during childhood and adolescence: Implications for teachers and parents. In F. Pajares \& T. Urdan (Eds.), Adolescence and Education: Vol. 5. SelfEfficacy Beliefs of Adolescents (pp. 339-367). Greenwich, CT: Information Age.

Pajares, F., Britner, S. L., \& Valiante, G. (2000). Relation between achievement goals and selfbeliefs of middle school students in writing and science. Contemporary Educational Psychology, 25, 406-422.

Pajares, F., \& Urdan, T. (Eds.). (2006). Adolescence and education: Vol. 5. Self-efficacy beliefs of adolescents. Greenwich, CT: Information Age. 
Schunk, D. H. (1983a). Developing children's self-efficacy and skills: The roles of social comparative information and goal setting. Contemporary Educational Psychology, 8, 7686.

Schunk, D. H. (1983b). Ability versus effort attributional feedback: Differential effects on selfefficacy and achievement. Journal of Educational Psychology, 75, 848-856.

Schunk, D. H. (1984). Sequential attributional feedback and children's achievement behaviors. Journal of Educational Research, 78, 29-34.

Schunk, D. H. (1987). Peer models and children's behavioral change. Review of Educational Research, 57, 149-174.

Schunk, D. H., \& Pajares, F. (2005). Competence perceptions and academic functioning. In A. J. Elliot \& C. S. Dweck (Eds.), Handbook of competence and motivation (pp. 85-104). New York: The Guilford Press.

Stipek, D., \& Gralinski, J. H. (1996). Children's beliefs about intelligence and school performance. Journal of Educational Psychology, 88, 397-407.

Thoman, D. B., White, P. H., Yamawaki, N., \& Koishi, H. (2008). Variations of gender-math stereotype content affect women's vulnerability to stereotype threat. Sex Roles, 58, 702712.

Thursby, J., \& Thursby, M. (2006, December 8). Where is the new science in corporate R\&D? Science, 314, 1547-1548.

Usher, E. L., \& Pajares, F. (2006). Sources of academic and self-regulatory efficacy beliefs of entering middle school students. Contemporary Educational Psychology, 31, 125-141.

Usher, E. L., \& Pajares, F. (2008). Sources of self-efficacy in school: Critical review of the literature and future directions. Review of Educational Research, 78, 751-796. 
Usher, E. L., \& Pajares, F. (2009). Sources of self-efficacy in mathematics: A validation study. Contemporary Educational Psychology, 34, 89-101.

Wood, R., \& Bandura, A. (1989). Impact of conceptions of ability on self-regulatory mechanisms and complex decision making. Journal of Personality and Social Psychology, 56, 407-415.

Zeldin, A. L., Britner, S. L., \& Pajares, F. (2008). A comparative study of the self-efficacy beliefs of successful men and women in mathematics, science, and technology careers. Journal of Research in Science Teaching, 45, 1036-1058.

Zeldin, A. L., \& Pajares, F. (2000). Against the odds: Self-efficacy beliefs of women in mathematical, scientific, and technological careers. American Educational Research Journal, 37, 215-246. 


\section{Footnote}

${ }^{1}$ The charter school offered a non-traditional curriculum, focused heavily on STEM subjects. This was in contrast to the curriculum required by the state and the county, which required Grade 9 students to take biology, Grade 10 students to take chemistry, and Grade 11 students to take physics. Students applied for the charter school, and those who were enrolled were chosen from a random lottery draw. 
- Explored profiles of adolescents' sources of self-efficacy.

- Profiles differentially related to science self-efficacy and grades.

- Grade level predicted membership into the profiles .

- Implicit theories of ability predicted membership into the profiles. 

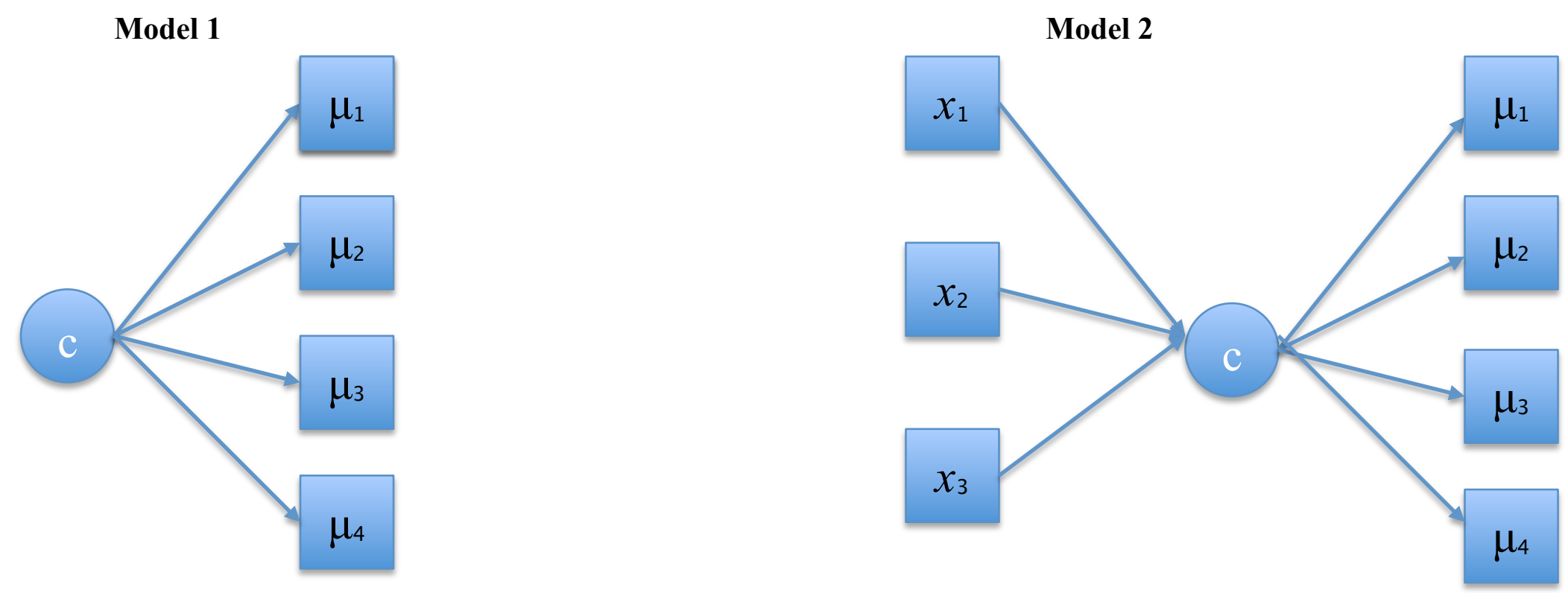

Figure 1. Path diagram of the latent profile analysis models. $\mu_{1}$ to $\mu_{4}$ denote the four sources of science self-efficacy. $C$ denotes the latent categorical variable, which classifies students according to their profile on the sources of science self-efficacy. The covariates in Model 2 are denoted by $x_{1}$ to $x_{3}$. In the present study, $C=4$, indicating that four profiles emerged. Also, the covariates were gender, grade level, and implicit theory of ability. 


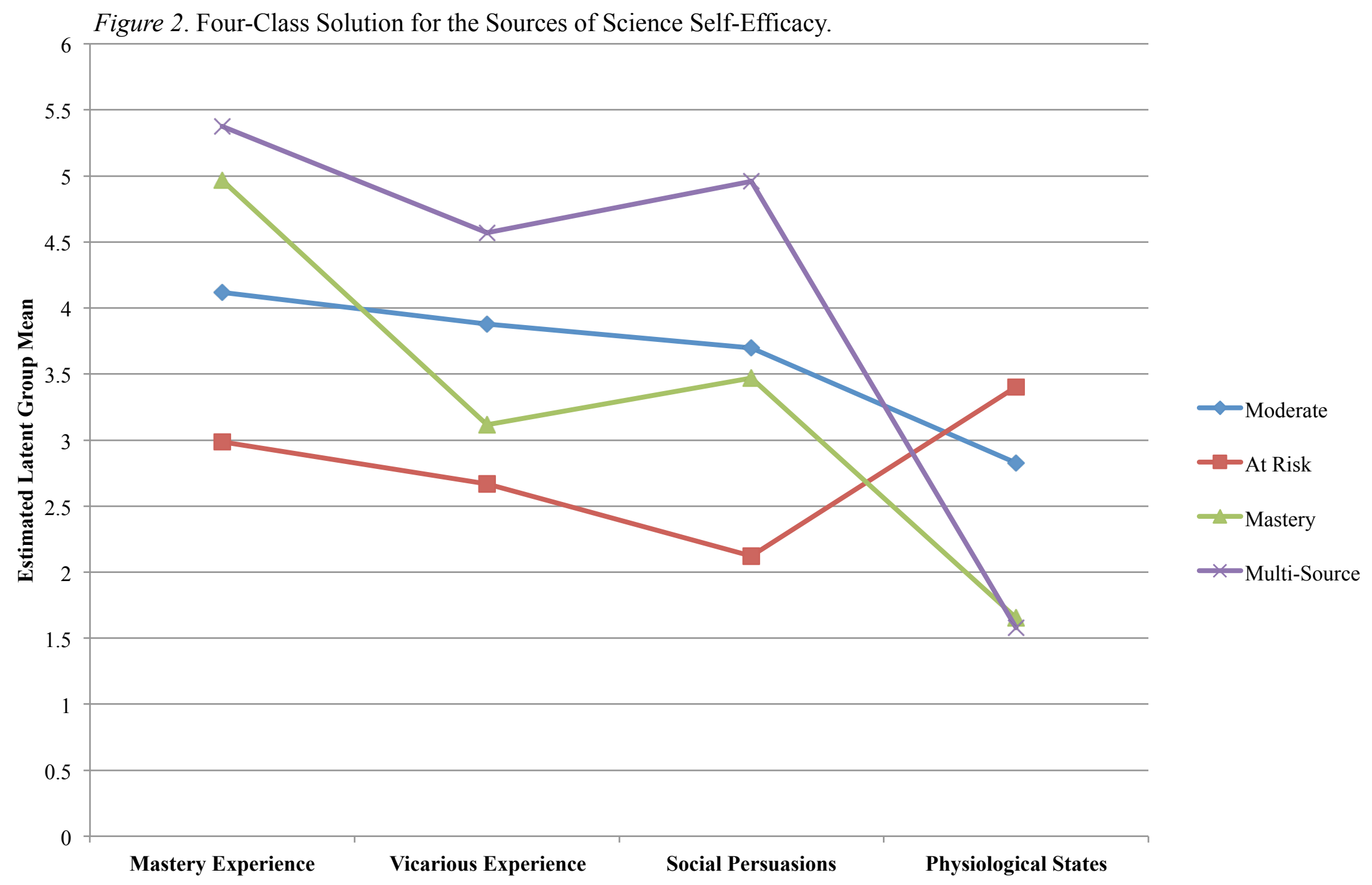

Note. Moderate: $n=357$ (29.1\%); At Risk: $n=341$ (27.8\%); Mastery: $n=280(22.9 \%)$; Multi-Source: $n=247$ (20.2\%). 
Figure 3. Z-score Means of Science Self-Efficacy and Science Achievement by Profile for the 4-Factor Model.

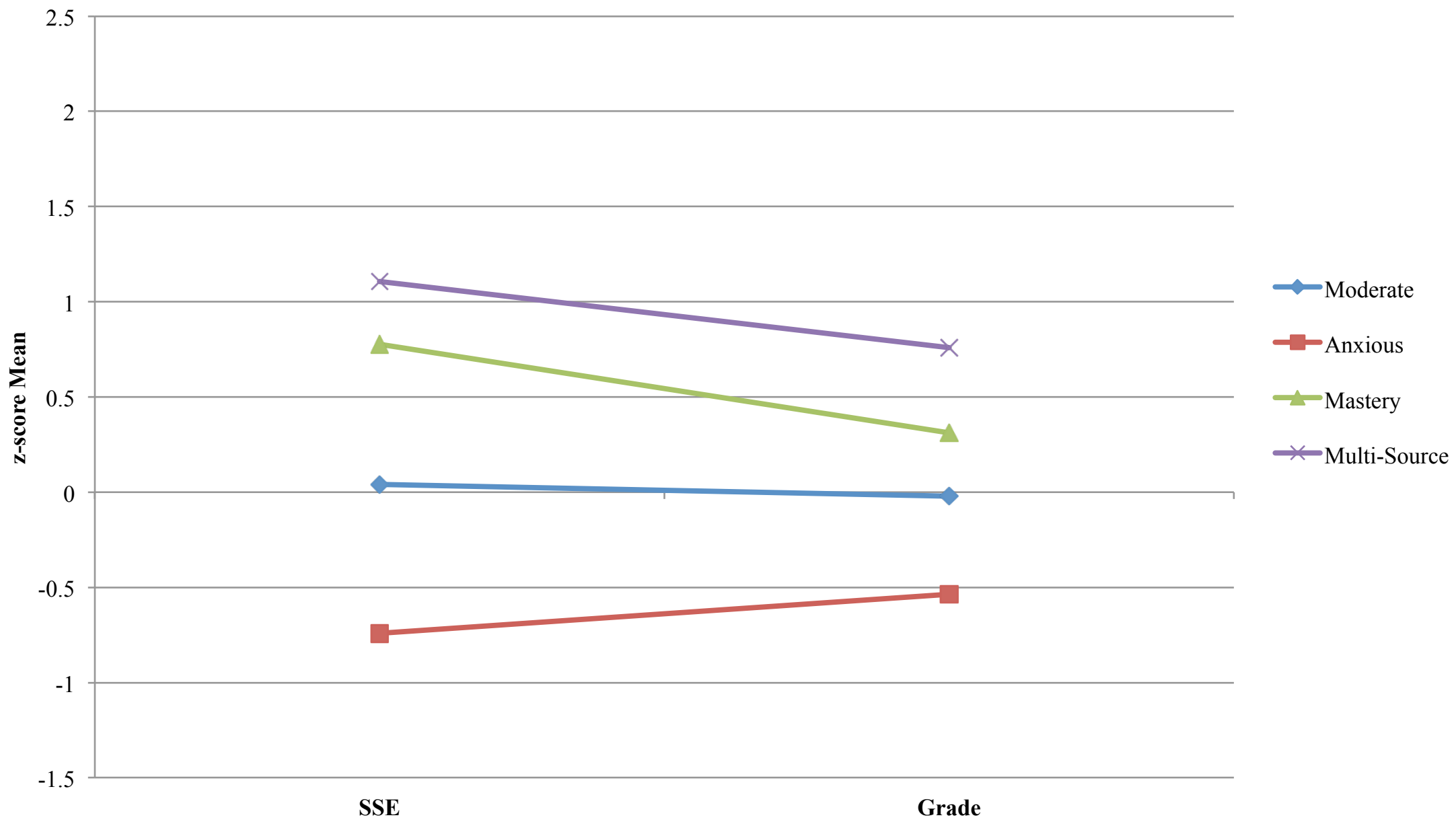

Note. Means in the same ellipses are not statistically different from each other (at the $p<.05$ level). SSE $=$ Science Self-Efficacy; Grade $=$ Science Grade (out of 100 points). 


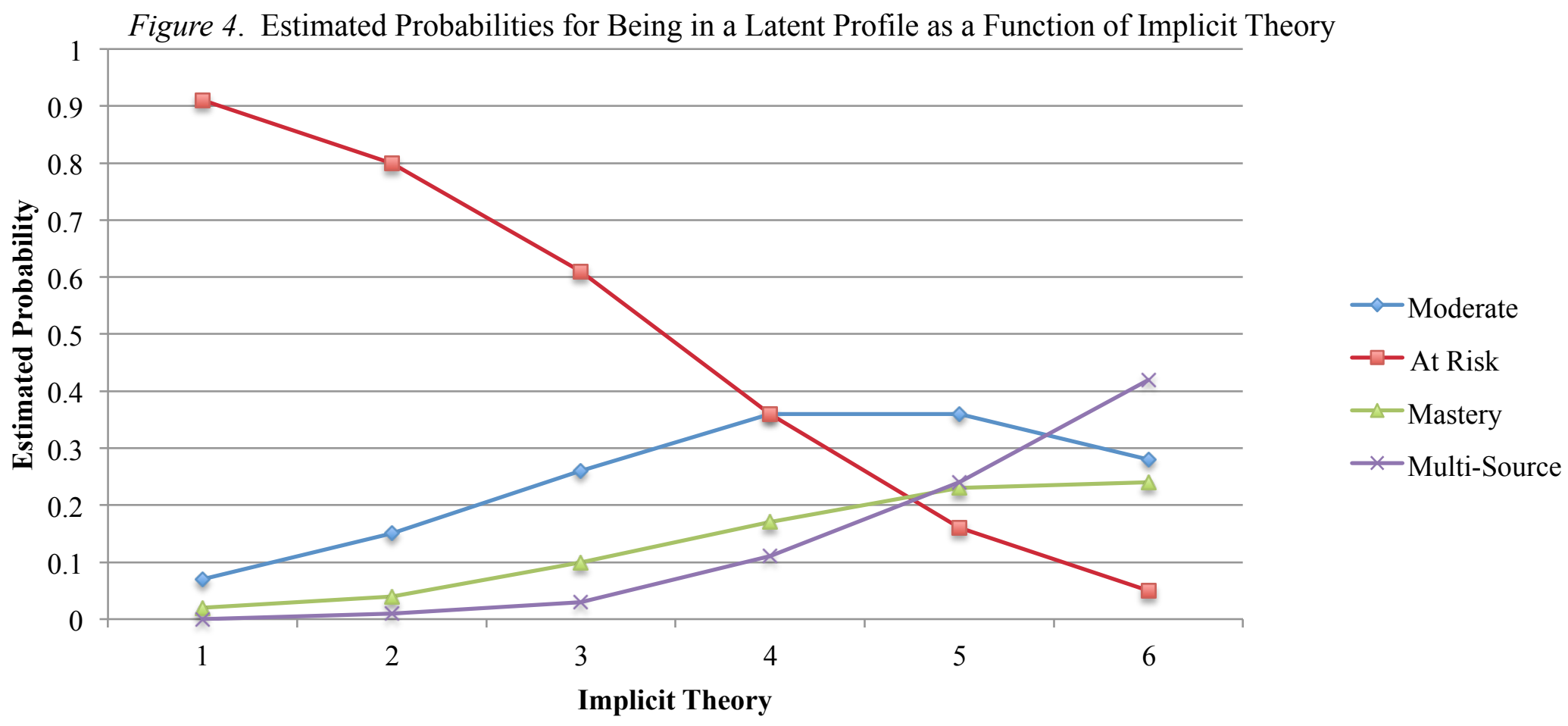

Note. Higher scores on the Implicit Theory scale refer to more incremental beliefs about ability. 


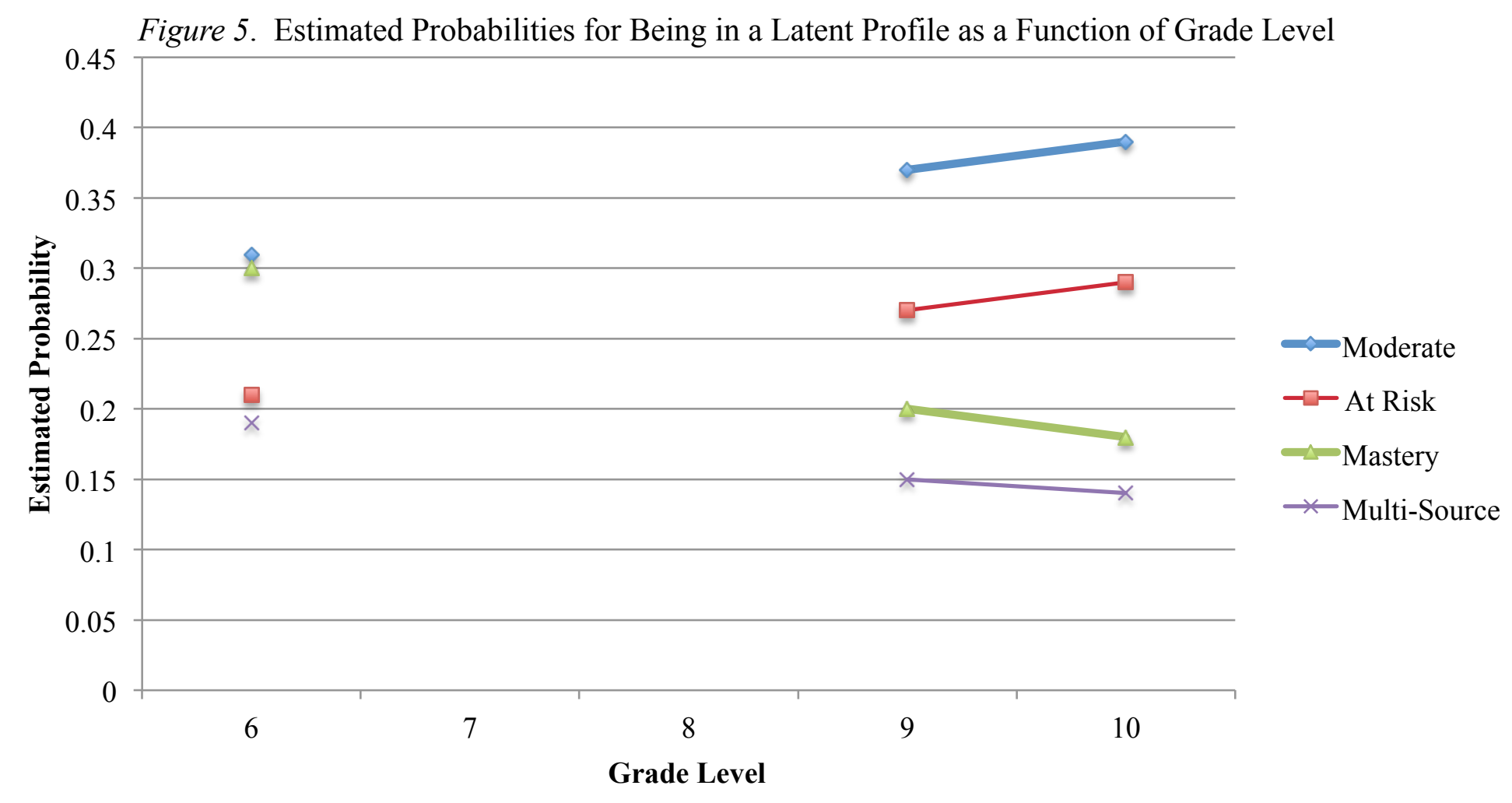

Note. Because no data were collected for Grades 7 and 8, these points are left blank. 
Table 1

Description of Participants and Settings

\begin{tabular}{ccccccccc}
\hline School & N & \% Female & \% White & \% Black & \% Asian & \% Hispanic & \% ESOL & $\%$ FRL \\
\hline Regular High School & 454 & 49 & 53 & 17 & 20 & 8 & 3 & 20 \\
STEM Charter High School & 263 & 38 & 31 & 16 & 39 & 12 & N/A & 23 \\
Middle School & 508 & 42 & 48 & 16 & 19 & 10 & 3 & 28 \\
\hline
\end{tabular}

Note. Because student self-report racial/ethnic data in the charter school were not available at the time of the study, teachers compiled this information on their own. ESOL=English for Speakers of Other Languages. FRL=Free and Reduced-price Lunch. 
Table 2. Goodness of Fit Indexes

\begin{tabular}{ccccccc}
\hline $\begin{array}{c}\text { Number of } \\
\text { Groups }\end{array}$ & Loglikelihood & $\begin{array}{c}\text { Number of Free } \\
\text { Parameters }\end{array}$ & BIC & $p$ LMR & Entropy & $\begin{array}{c}\text { Smallest Class } \\
\text { Frequency } \\
\text { (Relative Frequency) }\end{array}$ \\
\hline 2 & -6773 & 17 & 13667 & .0000 & .794 & $600(.490)$ \\
3 & -6571 & 26 & 13328 & .0003 & .786 & $266(.217)$ \\
4 & -6454 & 35 & 13157 & .0096 & .746 & $247(.202)$ \\
5 & -6364 & 44 & 12901 & .3392 & .773 & $93(.076)$ \\
6 & -6304 & 53 & 12986 & .1733 & .778 & $62(.051)$ \\
\hline
\end{tabular}

Note. $\quad \mathrm{BIC}=$ Bayesian Information Criterion $;$ LMR $=p$ values for the Lo-Mendell-Rubin likelihood ratio test for K versus K-1 classes. Smallest Class = size of the smallest latent class and the relative proportion. $N=1225$. 
Table 3

Estimated probabilities for being in a profile as a function of grade level and implicit theory

\begin{tabular}{lccccccc}
\hline \multirow{2}{*}{ Profile } & \multicolumn{3}{c}{ Grade Level } & & \multicolumn{3}{c}{ Implicit Theory } \\
\cline { 2 - 3 } \cline { 6 - 8 } & 6 & 9 & 10 & & 3.4 & 4.4 & 5.4 \\
\hline Multi-Source & .19 & .15 & .14 & & $.08 / .06 / .05$ & $.19 / .15 / .14$ & $.35 / .31 / .30$ \\
Mastery & .30 & .20 & .18 & & $.21 / .13 / .11$ & $.30 / .20 / .18$ & $.32 / .24 / .22$ \\
Moderate & .31 & .37 & .39 & & $.28 / .30 / .31$ & $.31 / .37 / .39$ & $.26 / .34 / .37$ \\
At Risk & .21 & .27 & .29 & & $.43 / .51 / .54$ & $.21 / .27 / .29$ & $.07 / .11 / .12$ \\
\hline
\end{tabular}

Note. Probability values for grade level were calculated holding implicit theory at its mean of 4.4. Implicit theory probability

values were calculated for values 1 SD below and above the mean. Values for implicit theory are listed in the format

Grade 6/Grade 9/Grade 10 